\title{
Association Between a Low Carbohydrate Diet, Quality of Life, and Glycemic Control in Australian Adults Living With Type 1 Diabetes: Protocol for a Mixed Methods Pilot Study
}

Janine Paul ${ }^{1,2}$, BHumanMvt, GradCertDiabEd, MSc; Rati Jani ${ }^{2}$, PhD; Peter Davoren ${ }^{1}$, MD; Catherine Knight-Agarwal ${ }^{2}$, $\mathrm{PhD}$

${ }^{1}$ Diabetes and Endocrinology, Gold Coast University Hospital and Health Service, Southport, Australia

${ }^{2}$ Faculty of Health, University of Canberra, Bruce, Australia

Corresponding Author:

Janine Paul, BHumanMvt, GradCertDiabEd, MSc

Diabetes and Endocrinology

Gold Coast University Hospital and Health Service

1 Hospital Boulevard

Southport, 4215

Australia

Phone: 61756874779 ext 74779

Fax: 61756874399

Email: u3189207@uni.canberra.edu.au

\section{Abstract}

Background: Globally, the prevalence of type 1 diabetes mellitus (T1DM) is rising. In 2020, a total of 124,652 Australians had T1DM. Maintaining optimal glycemic control (hemoglobin $\mathrm{A}_{1 \mathrm{c}} \leq 7.0 \%, \leq 53 \mathrm{mmol} / \mathrm{mol}$ ) on a standard carbohydrate diet can be a challenge for people living with T1DM. The Diabetes Complications and Control Trial established that macrovascular and microvascular complications could be reduced by improving glycemic control. Recent studies have found that a very low or low carbohydrate diet can improve glycemic control. However, the overall evidence relating to an association between a very low or low carbohydrate diet and glycemic control in people living with T1DM is both limited and mixed. In addition, research has suggested that a reduced quality of life due to anxiety and depression adversely influences glycemic control. Despite a potential link between a very low or low carbohydrate diet and optimal glycemic control, to our knowledge, no research has examined an association between a low carbohydrate diet, quality of life, and glycemic control, making this study unique in its approach.

Objective: The study aims to develop a validated diabetes-specific quality of life questionnaire for use in Australian adults with T1DM and to determine if an association exists between a low carbohydrate diet, quality of life, and glycemic control in Australian adults living with T1DM.

Methods: This cross-sectional study will be conducted in a tertiary hospital outpatient setting and will consist of 3 phases: phase 1, online Australian diabetes-specific quality of life questionnaire development and piloting (25-30 adults with T1DM); phase 2, questionnaire validation (364 adults with T1DM); and phase 3, a 12-week dietary intervention to determine if an association exists between a low carbohydrate diet, quality of life, and glycemic control in adults with T1DM (16-23 adults with T1DM). The validation of the study-developed Australian diabetes-specific quality of life questionnaire, and changes in hemoglobin $\mathrm{A}_{1 \mathrm{c}}$ and quality of life in adults with T1DM while undertaking a low carbohydrate diet over 12 weeks will be the primary outcomes of this study.

Results: Phase 1 of the study is currently open for recruitment and has recruited 12 participants to date. It is anticipated that the first results will be submitted for publication in November 2021. Presently, no results are available.

Conclusions: This study is the first of its kind in that it will be the first to generate a new validated instrument, which could be used in evidence-based practice and research to understand the quality of life of Australian adults with T1DM. Second, the low carbohydrate dietary intervention outcomes could be used to inform clinicians about an alternative approach to assist T1DM adults in improving their quality of life and glycemic control. Finally, this study could warrant the development of an evidence-based low carbohydrate dietary guideline for adults living with T1DM with the potential to have a profound impact on this population.

Trial Registration: ClinicalTrials.gov NCT04213300; https://clinicaltrials.gov/ct2/show/NCT04213300 
International Registered Report Identifier (IRRID)： PRR1-10.2196/25085

(JMIR Res Protoc 2021;10(3):e25085) doi: $10.2196 / 25085$

\section{KEYWORDS}

type 1 diabetes; diet; low carbohydrate; HbA1c; adults; quality of life

\section{Introduction}

There are more than 420 million people worldwide, aged 20 to 79 years, living with type 1 diabetes mellitus (T1DM) [1]. In 2020, a total of 124,652 Australians had T1DM [2]. As the number of people with this autoimmune condition increases, so does the prevalence of those with suboptimal glycemic control [3].

Glycemic control is evaluated by glycated hemoglobin $\left(\mathrm{HbA}_{1 \mathrm{c}}\right)$, which provides an average blood glucose level over a period of 2 to 3 months [4]. The target for optimal glycemic control for people with T1DM is $\leq 7.0 \%$ ( $\leq 53 \mathrm{mmol} / \mathrm{mol})$ [5]. In 2015, data from T1DM registries from 19 countries across Europe, North America, and Australasia ( $\mathrm{N}=324,501)$ showed that only $46 \%$ of adults (aged $\geq 25$ years) with $\mathrm{T} 1 \mathrm{DM}$ achieved the $\mathrm{HbA}_{1 \mathrm{c}}$ target of $<7.0 \%$ [6].

Suboptimal glycemic control increases the risk of development and progression of various diabetes-related complications including hypoglycemia, diabetic ketoacidosis neuropathy, nephropathy, retinopathy, and cardiovascular disease [1].

The Diabetes Control and Complications Trial aimed to determine the long-term frequency and severity of chronic complications in individuals living with T1DM using intensive insulin therapy with the goal of maintaining blood glucose levels as close to normal range as possible. This seminal work convincingly demonstrated the effectiveness of intensive insulin therapy in reducing the long-term complications of T1DM and improving the prospects for a healthy life span for individuals living with T1DM. This landmark study established the glycemic control guidelines used today [7].

A recent systematic review reported the incidence and prevalence of diabetic ketoacidosis in adults with T1DM from 3 continents [8]. In this review, 19 studies ( 1 randomized control trial and 18 cross-sectional studies) containing similar numbers of males and females, were included, with over $80 \%$ of participants being White. The review found that adults aged 18 to 25 years had the highest prevalence of diabetic ketoacidosis (100-120 cases per 1000 in studies with 12 months' recall) compared to those older than 65 years who had the lowest prevalence of diabetic ketoacidosis (38-60 cases per 1000 in studies with a 12-month recall) [8].

Traditionally, it has been recommended that people living with T1DM consume $45 \%$ to $60 \%$ of total energy intake from carbohydrate sources [9]. Dietary approaches commonly used to manage glycemic control include carbohydrate counting, which matches insulin-to-carbohydrate intake, and/or a low glycemic index diet [10,11].

Recently, there has been a growing focus on the utility of a low carbohydrate diet to manage glycemic control in individuals living with T1DM $[12,13]$. This dietary management strategy has been thoroughly investigated in people living with type 2 diabetes mellitus (T2DM) [14,15]. However, there is a paucity of evidence regarding T1DM.

A very low carbohydrate diet is defined as 0-50 $\mathrm{g}$ per day or $<10 \%$ of the total daily energy intake [16], while a low carbohydrate diet is defined as $<130 \mathrm{~g}$ per day or $<26 \%$ of the total daily energy intake $[16,17]$. Schmidt et al [12] conducted a randomized crossover study to examine the effects of a low carbohydrate diet ( $<100 \mathrm{~g}$ carbohydrate/day) compared to a high carbohydrate diet ( $>250 \mathrm{~g}$ carbohydrate/day) on glycemic control. Participant baseline characteristics included White adults from Denmark (male: 6/14, 43\%; female: 8/14, 57\%; 14 with T1DM; mean age 44 years, SD 12 years). Participant median diabetes duration was 19 (range 13-32) years, and the $\mathrm{HbA}_{1 \mathrm{c}}$ was $7.5 \%$ (range 7.2\%-7.6\%). Participants undertook two, 12-week interventions separated by a 12 -week "washout" period, with 10 of the 14 participants completing the study. The study found that a low carbohydrate diet compared to a high carbohydrate diet did not significantly improve $\mathrm{HbA}_{1 \mathrm{c}}$, but did stabilize glucose variability and reduce hypoglycemia frequency $(P<.001)$ [12].

There is only 1 systematic review that has examined the association between very low and low carbohydrate diets and glycemic control in people living with T1DM [18]. It included a total of 9 original studies: 2 randomized controlled trials [19,20], 2 quasi pre- or post-cross-sectional [21,22] studies, 4 case series [23-26], and 1 case report [27]. Participants ranged from 14 to 65 years of age and resided in the United Kingdom, the United States, Europe, Australia, or New Zealand. Fewer than half the studies $(3 / 9)$ reported a significant improvement in $\mathrm{HbA}_{1 \mathrm{c}}(0.7 \%-2.4 \% ; P<.05)$ [18]. The difference in sample sizes, study methodologies, and participant baseline characteristics (age, gender, ethnicity, and diabetes duration) may account for these nonsignificant results. Despite a paucity of evidence, associations have been observed between very low and low carbohydrate diets with good glycemic control in individuals living with T1DM [13,19,23-26]. However, these findings are relatively mixed [12,13,19,21,23-26,28-31].

Very little research has been conducted in the area of a low carbohydrate diet and quality of life (QoL) in adults living with T1DM. Additional research is needed to determine if there is a link between these 2 variables because T1DM has been reported to be the cause of a reduced QoL [32]. Roy and Lloyd [33] conducted a systematic review to examine the evidence for rates of depression within the diabetes population. The authors reported the prevalence of depression to be 3 times higher in people living with T1DM when compared to those without it (12\% vs. $3 \%$, respectively). In Australia, it has been found that $41 \%$ of adults ( $>18$ years old) living with T1DM experience 
diabetes-related anxiety, depression, and stress [34]. In turn, these psychological issues have been linked with suboptimal glycemic control and diabetes complications, thus contributing to diminished QoL.

There is no agreed explanation of QoL $[35,36]$ as demonstrated by the numerous existing definitions reported in the literature [36-40]. There is however, universal agreement that QoL is a multidimensional, subjective construct that includes at least three domains: physical (eg, pain), psychological (eg, body image), and social (eg, relationships) well-being [35-37,41-44]. Common QoL definitions do not appear to use a holistic lifestyle approach and fail to consider dietary well-being, a key aspect of QoL for individuals living with T1DM [45].

QoL is commonly assessed in T2DM populations [46,47] but rarely in adults living with T1DM [48]. Pereira et al [47] conducted a systematic review to determine the relationship between QoL and $\mathrm{HbA}_{1 \mathrm{c}}$ in those living with T1DM. The review consisted of 110 studies (78 observational and 32 interventional) from countries in North America and Europe, and included 69 T1DM studies, 35 T2DM studies, and 6 T1DM and T2DM studies. All studies included an approximately 1:1 male to female participant ratio, with an age range from 5 to 70 years and a diabetes duration from 2 to 29 years. QoL instruments used included the Diabetes Quality of Life Measure (DQOL) [49] and the Diabetes Quality of Life for Youth (DQOLY) measure [50]. Baseline $\mathrm{HbA}_{1 \mathrm{c}}$ for T1DM interventional and observational studies ranged from $6.1 \%$ to $11.0 \%$ and from $7.0 \%$ to $12.2 \%$, respectively. Endpoint $\mathrm{HbA}_{1 \mathrm{c}}$ ranges for interventional and observational studies were reduced from $5.9 \%$ to $9.5 \%$ and from $7.1 \%$ to $9.6 \%$, respectively. Despite a reduction in $\mathrm{HbA}_{1 \mathrm{c}}$, only $41 \%$ of participants reported an improvement in QoL, suggesting that people living with T1DM generally perceive this as unsatisfactory [47].

The Diabetes-Specific Quality of Life Scale (DSQOLS) is the only validated QoL instrument for adults living with T1DM [48]. Nevertheless, it is not suitable for assessing the dietary well-being of Australian adults because the instrument fails to consider carbohydrate counting, which is a fundamental skill used by those living with T1DM in Australia to manage insulin and blood glucose levels [51]. The instrument also neglects to assess food intake satisfaction, which is another important aspect of dietary well-being [45]. These factors are likely to influence QoL outcomes; therefore, the development of a new T1DM-specific QoL instrument that includes the four domains of physical, psychological, social, and dietary well-being is being proposed.

To address the identified deficit in the literature, our study aims to develop and validate a diabetes-specific QoL questionnaire for use in Australian adults with T1DM and to determine if an association exists between a low carbohydrate diet, QoL, and glycemic control.

\section{Methods}

\section{Study Design and Ethics}

This cross-sectional study will be conducted in 3 phases. Study phase 1 will include online Australian diabetes-specific QoL questionnaire development and piloting. Study phase 2 will consist of Australian diabetes-specific QoL questionnaire validation with the following 2 subphases: subphase $2 \mathrm{a}$, which will include initial validation with an online diabetes-specific QoL questionnaire; study subphase $2 b$, which will include online questionnaire validation of the Australian diabetes-specific QoL, the Medical Outcomes Study 36-Item Short Form Health Survey (MOS SF-36), DQOL, and Problem Areas in Diabetes (PAID-20) questionnaires; study phase 3 will include intervention, which will be aimed at determining if an association exists between a low carbohydrate diet, QoL, and glycemic control in adults living with T1DM.

Ethics approval has been obtained from the Gold Coast Hospital and Health Service (GCHHS) Human Research Ethics Committee (HREC) and the University of Canberra HREC. Ethics approval numbers for study phase 1 and 2 are HREC/2019/QGC/54049 and HREC/2019/UC/2223, respectively. The approval numbers for study phase 3 are HREC/2019/QGC/60717 and HREC/2020/UC/4691. The study was registered at ClinicalTrials.gov (NCT04213300).

\section{Participant Recruitment}

Participant recruitment for each study phase will be facilitated by both face-to-face and online (eg, social media and email) approaches. Information posters will be placed across the GCHHS patient waiting areas containing the principal investigator's (JP) contact details (email, phone number) and a questionnaire QR (quick response) code.

\section{Study Outline}

First, approval for the study was gained from the Gold Coast Hospital and Health Service (GCHHS) HREC and the University of Canberra HREC.

\section{Study Phase 1}

Study phase 1 will consist of the development and piloting of the online Australian diabetes-specific QoL questionnaire. In all, 25-30 adults ( $\geq 18$ years old) with T1DM will be included. Data will be collected via an online questionnaire (10-15 minutes) followed by a face-to-face or online interview (20-30 minutes), with the period of data collection lasting 1 month. The face-to-face or online interview location will be the Gold Coast University Hospital, Outpatient Department, Diabetes Resource Centre or the Zoom online platform (the participants may choose their preferred interview method), respectively. Interview data will be audio-recorded, transcribed verbatim, coded, and parsed for common themes. A summary of key suggestions for revising the online questionnaire to be used in study subphases $2 \mathrm{a}$ and $2 \mathrm{~b}$ will be produced.

\section{Study Phase 2}

Study phase 2a will be the initial validation of the online Australian diabetes-specific QoL questionnaire. In all, 364 adults 
( $\geq 18$ years old) with T1DM will be included. Data will be collected via an online questionnaire (estimated completion time 10-12 minutes). Participants will have access to the questionnaire for 2 weeks. If the questionnaire link expires, the participant may request a new link by contacting JP. The data collection period for this phase will last 3 months.

Study phase $2 \mathrm{~b}$ will consist of subsequent validation of the Australian diabetes-specific QoL questionnaire using the MOS SF-36, the DQOL, and the PAID-20 questionnaires. Three months after study subphase $2 \mathrm{a}$ is completed, study subphase $2 \mathrm{~b}$ will commence. Participants from study subphase $2 \mathrm{a}$ will be invited by email to complete the same online questionnaire for a second time. In addition, they will be asked to complete the MOS SF-36 [52], DQOL [49], and the PAID-20 [53] questionnaires. Responses will be analyzed to determine the statistical reliability and validity of the Australian diabetes-specific QOL questionnaire. In all, 100 adults $(\geq 18$ years old) with T1DM will be included. Data will be collected via an online questionnaire (estimated completion time 15-18 minutes). Participants will have access to the questionnaire for 2 weeks. If the questionnaire link expires, the participant may request a new link by contacting JP. The data collection period for this phase will last 3 months.

\section{Study Phase 3}

Study phase 3 will comprise preintervention, intervention, and postintervention procedures. The overall aim of this phase is to determine if an association exists between a low carbohydrate diet, QoL, and glycemic control in adults living with T1DM through use of a cross-sectional cohort study. In all, 16-23 adults ( $\geq 18$ years old) with T1DM will be included.

The preintervention period will begin 1 week prior to commencing the intervention procedure. Participants will attend the study hospital for approximately 3 hours to do the following: complete the study consent form (hard copy), if not already completed; discuss the intervention process ensuring they have a clear understanding of what is required during all phases of the intervention; receive an information kit containing the study procedure, the research team (endocrinologist [PD], credentialed diabetes educator [CDE; DI], and diabetes dietitian [JP]) and Gold Coast Hospital Emergency Department contact details, a food diary, a sick day management plan, and support services (in case any psychological distress is experienced during the study); complete the online Australian diabetes-specific QoL questionnaire; have weight $(\mathrm{kg})$, height $(\mathrm{cm})$, and glycated hemoglobin $\left(\mathrm{HbA}_{1 \mathrm{c}}\right)$ recorded; receive continuous glucose monitoring system (CGMS) education and supply of CGMS equipment; apply the CGM sensor to their abdominal wall, attach the transmitter, and establish a connection between the transmitter and their own compatible smart device in order to enable recording and displaying of their glucose levels; and receive instruction on how to continue with their usual, daily routine, and be asked to commence recording what they eat and drink via a food diary. The day prior to commencing the intervention, participants will receive their individualized meal plans by email.

The intervention procedure will take place in the participants own environment and last 12 weeks. Participants will be expected to perform the following during the intervention period: follow the low carbohydrate dietary plan (dietary composition: $20 \%$ carbohydrate [ $<100 \mathrm{~g}$ ], protein $25 \%$, and fat $55 \%$ ) as prescribed by a diabetes dietitian, complete a daily food diary, test blood ketone levels weekly (at fasting), participate in a weekly endocrinologist appointment to discuss blood glucose levels and insulin adjustments by telephone, attend the diabetes dietitian appointment by telephone to discuss any concerns with the dietary plan, contact DI if having problems with the CGMS, and change the CGM sensor every 10 days.

The postintervention procedure will begin the day after the intervention has been completed, and participants will attend the study hospital for up to 90 minutes for the following: to record weight $(\mathrm{kg})$ and $\mathrm{HbA}_{1 \mathrm{c}}$ with $\mathrm{DI}$, to complete the online diabetes-specific QoL questionnaire and online patient global impression change questionnaire, and to participate in a face-to-face CGMS experience interview with JP.

\section{Participant Eligibility Criteria}

\section{Inclusion Criteria}

Study participants for each phase will self-identify against the following eligibility criteria: aged $\geq 18$ years, living with T1DM, and T1DM diagnosis for $\geq 1$ year. Study phase 3 includes 5 additional eligibility criteria that participants must meet: (1) use of multiple daily injections for insulin administration, (2) experience of at least one hypoglycemic episode since diagnosis, (3) knowledge of hypoglycemic management, (4) ability to test for blood ketones, and (5) knowledge of blood ketone management.

\section{Exclusion Criteria}

Ineligible participants will include the following: people living with T2DM; people living with gestational diabetes mellitus; people who administer insulin using a continuous subcutaneous insulin infusion; those living with a known food allergy; those with a history of an eating disorder; those with a BMI $<18.5$ $\mathrm{kg} / \mathrm{m}^{2}$; those aged $<18$ years; those who are pregnant or planning to conceive; those taking prescription medications, such as phentermine or corticosteroids; individuals with an active medical problem, such as a recent myocardial infarction, stroke or peripheral revascularization (within 3 months), active treatment of diabetic retinopathy, or recent serious infection (requiring in-hospital treatment or prolonged antibiotic therapy), that may hinder their ability to take part or may potentially affect study outcomes; those for whom written materials may be unsuitable (eg, vision-impaired or illiterate individuals); those unable to understand English; and those who fail to sign the participant consent form.

\section{Sample Size}

\section{Study Phase 1: Online Australian Diabetes-Specific QoL Questionnaire Development and Piloting}

Sample size data will be collected from approximately 25-30 adult participants with T1DM. This sample size is based on previous research [54] and has been deemed as sufficient to facilitate in-depth face-to-face interviews [55]. 
Study Phase 2: Online Australian Diabetes-Specific QoL Questionnaire Validation

This phase will include 2 subphases: $2 \mathrm{a}$ and $2 \mathrm{~b}$. Subphase $2 \mathrm{a}$ will involve initial validation. This will include the online Australian diabetes-specific QoL questionnaire and will require 364 adult participants with T1DM. This sample size has been calculated using the participant-to-item ratio method [56]. Subphase $2 \mathrm{~b}$ will involve subsequent validation. This will include the online Australian diabetes-specific QoL, MOS SF-36, DQOL, and PAID-20 questionnaires, and will require 100 responses to be collected for test-retest, convergent, and divergent validity statistical analysis. This sample size is based on biostatistician advice and other studies that have validated QoL instruments [49,57-59].

\section{Study Phase 3: The Low Carbohydrate Dietary Intervention}

A sample size of 16 has been calculated with a 0.05 significance level and power of 0.8 to detect a significant clinical difference of $1.0 \%$ in $\mathrm{HbA}_{1 \mathrm{c}}$. A $1.0 \%$ change in $\mathrm{HbA}_{1 \mathrm{c}}$ will be used because dietary changes alone have shown to improve $\mathrm{HbA}_{1 \mathrm{c}}$ by $1.0 \%$ [60]. To complete the study, 16 participants are required. To account for a $40 \%$ attrition rate [12], 23 participants will be the maximum number recruited.

\section{Data Privacy and Confidentiality}

Confidentiality and privacy of participant data will be restricted to JP. The strategy for identification, coding, and deidentification of participant data will involve recording the participants' name, email address, and contact phone number in an electronic master list stored at the hospital and retained for archiving purposes. All questionnaires in this study will be delivered using an online encrypted questionnaire platform to ensure participant responses are secure and confidential.

\section{Data Collection}

\section{Study Phase 1: Online Australian Diabetes-Specific QoL Questionnaire Development and Piloting}

Volunteering participants will consent to completing both the online questionnaire and a face-to-face interview. Table 1 outlines each questionnaire section and provides a brief description of what is included. The participants' pilot questionnaire link will be active for 2 weeks. A courtesy email reminder will be sent to those who have not completed or have partially completed the pilot questionnaire after 7 days. It is anticipated that the questionnaire will take 10-15 minutes. Once the pilot questionnaire is completed, the participant will be contacted via phone to arrange a suitable time for either a face-to-face interview at the study hospital or an online interview. It is estimated that the duration of the interview will be 20-30 minutes. Interviews will be undertaken by JP with the aid of a question guide to ensure a consistent approach is followed. Each interview will be audio-recorded and then transcribed verbatim. Common participant feedback will be documented and then reviewed by the research team. This feedback will be used to modify specific items identified as needing improved clarity and concision or to remove them due to irrelevance. The revised version of the online questionnaire will be used in study phase 2 , and subphases $2 \mathrm{a}$ and $2 \mathrm{~b}$.

Table 1. Study phase 1: online Australian diabetes-specific quality of life questionnaire completed by adults with type 1 diabetes mellitus ( $\mathrm{n}=25-30)$.

\begin{tabular}{|c|c|c|}
\hline Questionnaire section & Brief description of items & Source \\
\hline Section 1: information sheet ${ }^{\mathrm{a}}$ & Overview of the study & $\mathrm{N} / \mathrm{A}^{\mathrm{b}}$ \\
\hline Section 2: screening questions $\mathrm{s}^{\mathrm{c}}$ & Assessment of study eligibility & N/A \\
\hline Section 3: consent form ${ }^{\mathrm{a}}$ & Signed by participant & N/A \\
\hline $\begin{array}{l}\text { Section 4: Australian diabetes-specific quality of } \\
\text { life questions }{ }^{\mathrm{d}}\end{array}$ & $\begin{array}{l}\text { A } 28 \text {-item questionnaire containing } 4 \text { constructs measuring di- } \\
\text { abetes quality of life using a 10-point Likert scale from "very } \\
\text { strongly disagree to "very strongly agree" }\end{array}$ & Adapted from $[48,57]$ \\
\hline Section 5: sociodemographic covariates & $\begin{array}{l}\text { Data collection: gender, age, height, weight, diabetes duration, } \\
\text { occupation, level of education, etc }\end{array}$ & Adapted from [61-63] \\
\hline
\end{tabular}

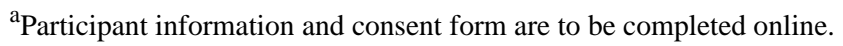

${ }^{\mathrm{b}} \mathrm{N} / \mathrm{A}$ : not applicable.

${ }^{\mathrm{c}}$ Screening questions are to be completed online. The response to each question is yes or no. The questions include the following: "I have type 1 diabetes mellitus," "I am 18 years or older," and "I have had type 1 diabetes mellitus for one year or longer."

${ }^{\mathrm{d}}$ Australian diabetes-specific quality of life questions were developed using previously validated questionnaires [48,57]; input will be collected by the research team through one-to-one participant interviews.
}

\section{Study Phase 2: Online Australian Diabetes-Specific QoL Validation}

Study phase 2 will be split into 2 subphases ( $2 \mathrm{a}$ and $2 \mathrm{~b}$ ). Study subphase $2 \mathrm{a}$ will consist of initial validation using the online Australian diabetes-specific QoL questionnaire. Data will be collected from 364 participants to support the statistical validation of the questionnaire. These 364 participants will be different to those who participated in study phase 1 . Table 2 shows each questionnaire section and a brief description of the section. After 7 days, a reminder email will be sent to those participants who have not commenced or have only partially completed the questionnaire. It is anticipated that the questionnaire will take 10-15 minutes to complete. Study subphase $2 b$ will consist of the subsequent validation using the online Australian diabetes-specific QoL, MOS SF-36, DQOL, 
and PAID-20 questionnaires. All participants $(\mathrm{N}=364)$ from study subphase $2 \mathrm{a}$ will receive an email 3 months after completing the initial online questionnaire requesting the completion of the questionnaire for a second time. This email will also request the participant to complete the online MOS SF-36 [52], DQOL [49], and PAID-20 questionnaires [53].

Table 2. Study phase 2a-initial validation: online Australian diabetes-specific quality of life questionnaire completed by adults with type 1 diabetes mellitus ( $\mathrm{N}=364)$.

\begin{tabular}{lll}
\hline Questionnaire section & Brief description of items & Source \\
\hline Section 1: information sheet ${ }^{\mathrm{a}}$ & Overview of the study & N/A $^{\mathrm{b}}$ \\
Section 2: screening questions & N/A \\
$\begin{array}{l}\text { Section 3: consent form } \\
\text { a }\end{array}$ & Signed by participant & N/A \\
$\begin{array}{l}\text { Section 4: Australian diabetes-specific quality } \\
\text { of life questionnaire }\end{array}$ & $\begin{array}{l}\text { A 28-item questionnaire containing 4 constructs measuring diabetes } \\
\text { quality of life using a 10-point Likert scale from "very strongly } \\
\text { disagree" to "very strongly agree" }\end{array}$ & Adapted from [48,57] \\
Section 5: sociodemographic covariates & $\begin{array}{l}\text { Data collection: gender, age, height, weight, diabetes duration, } \\
\text { occupation, level of education, etc }\end{array}$ & Adapted from [61-63] \\
\hline
\end{tabular}

${ }^{\mathrm{a}}$ Participant information and consent form are to be completed online.

${ }^{\mathrm{b}} \mathrm{N} / \mathrm{A}$ : not applicable.

${ }^{\mathrm{c}}$ Screening questions are to be completed online. The response to each question is yes or no. The questions include the following: "I have type 1 diabetes mellitus," "I am 18 years or older," and "I have had type 1 diabetes mellitus for one year or longer."

Participants will be supplied with a link for access to all 4 convergent, and divergent validity. Table 3 outlines the questionnaires. Of the 364 participants, 100 participants will questionnaires to be completed as part of the subsequent be needed to complete the questionnaire to establish test-retest, validation process.

Table 3. Study phase $2 \mathrm{~b}$-subsequent validation: online Australian diabetes-specific quality of life, MOS SF-36, DQOL, and PAID-20 questionnaires completed by adults with type 1 diabetes mellitus $(n=100)$.

\begin{tabular}{|c|c|c|}
\hline Questionnaire section & Brief description of items & Source \\
\hline Section 1: information sheet ${ }^{\mathrm{a}}$ & Overview of the study & $\mathrm{N} / \mathrm{A}^{\mathrm{b}}$ \\
\hline Section 2: screening questions ${ }^{\mathrm{c}}$ & Assessment of study eligibility & N/A \\
\hline Section 3: consent form ${ }^{\mathrm{a}}$ & Signed by participant & N/A \\
\hline
\end{tabular}

Section 4: Australian diabetes-specific quality A 28-item questionnaire containing 4 constructs measuring diabetes Adapted from [48,57] of life questionnaire quality of life using a 10-point Likert scale from "very strongly disagree" to "very strongly agree"

Section 5: MOS SF-36 ${ }^{\mathrm{d}}$

Section 6: DQOL ${ }^{\mathrm{e}}$

Section 7: PAID-20

Section 8: sociodemographic covariates
Measures of physical and psychological constructs of general wellbeing with varying response scales

A 43-item instrument consisting of 4 constructs (satisfaction, impact, social/vocational worry, diabetes-related worry). A Likert response format from "very satisfied" to "not satisfied" for the satisfaction construct and from "never" to "always" for the other constructs.

A 20-item questionnaire that measures diabetes-related distress. Each item addresses a different issue associated with diabetes. A 5-point response scale is used from "not a problem to "serious problem".

Data collection: gender, age, height, weight, diabetes duration, occupation, level of education, etc
Adapted from [61-63]

${ }^{\mathrm{a}}$ Participant information and consent form are to be completed online.

${ }^{\mathrm{b}} \mathrm{N} / \mathrm{A}$ : not applicable.

${ }^{\mathrm{c}}$ Screening questions are to be completed online. The response to each question is yes or no. The questions include the following: "I have type 1 diabetes mellitus," "I am 18 years or older," and "I have had type 1 diabetes mellitus for one year or longer."

${ }^{\mathrm{d}}$ MOS SF-36: Medical Outcomes Study 36-Item Short Form Health Survey.

${ }^{\mathrm{e} D Q O L}$ : Diabetes Quality of Life Measure.

${ }^{f}$ PAID-20: Problem Areas in Diabetes. 


\section{Phase 3: The Low Carbohydrate Dietary Intervention}

Phase 3 is planned to commence in February 2021. Potential participants will volunteer to participate in the study by responding to the contact details of JP on information flyers in the hospital patient waiting areas or provided to them by an endocrinologist or CDE. Potential study participants may include those who participated in study phase 1 or 2 but may also include those who did not necessarily participate in any of the previous study phases. Potential participants who contact JP regarding study participation will have a verbal discussion to ensure they meet the inclusion criteria. Subsequently, the following study requirements for participants will be explained: following a low carbohydrate diet for 12 weeks, using a CGMS for 12 weeks, testing blood ketones weekly, completing a daily food diary, participating in 2 in-person study hospital appointments, and participating in weekly diabetes dietitian and endocrinologist telephone appointments. If the participant provides verbal consent to be included in the study, a preintervention appointment date and time will be organized with the participant to attend the study hospital 1 week prior to commencing the intervention. The participant will be sent an email to confirm the appointment date and time as well as a participant information and a consent form. The consent form may be completed and returned to JP by email prior to or at the preintervention appointment. Two days prior to the preintervention appointment, JP will telephone the participant as a courtesy reminder of the appointment date and time.

\section{Preintervention Procedure}

The preintervention appointment will be conducted by a CDE at the study hospital. The CDE will ensure the participant consent form has been completed before commencing the preintervention appointment. The CDE will discuss the study procedure to ensure the participant understands what is required during all phases of the intervention. The CDE will record the participants' weight $(\mathrm{kg})$ and height $(\mathrm{cm})$ using a seca 763 electronic measuring station. This information will be recorded on a participant data collection form which will be used preand postintervention. An $\mathrm{HbA}_{1 \mathrm{c}}$ test will be conducted using a DCA Vantage Analyzer (Siemens Healthineers). Participants will complete the online Australian diabetes-specific QoL questionnaire using a hospital computer. The $\mathrm{CDE}$ will provide each participant with a Dexcom G6 CGMS kit. The kit includes a transmitter, sensors, and a sensor applicator, as provided by Dexcom. Novice CGMS participants will be taught how to use the device. During this appointment, the participant will apply the CGM sensor to their abdominal wall, attach the transmitter, and establish a connection between the transmitter and their own compatible smart device to enable recording and displaying of their glucose levels. Participants glucose levels will then record and display glucose level via the Dexcom G6 application, which the participant will install onto their compatible smart device. The Dexcom G6 CGMS kit will be retained by the participant at the completion of the study. Participants will not use their own personal glucose monitor during the study to test blood glucose levels. However, the participant will use it weekly to test blood ketones. The participant will also be required to use their own blood ketone strips for this test.
Participants will continue with their usual, daily routine; however, they will commence recording food and fluid consumption in a food diary. Participants will be required to complete the daily food diary 1 week prior to commencing the intervention and for the 12 weeks of the intervention. The participant will email this information to the diabetes dietitian weekly to ensure these records are being maintained, as the information will be used in the final data analysis stage. Participants' individualized meal plans will be emailed to each participant the day prior to commencing the intervention. Each participant will also be provided with digital kitchen scales and measuring cups and spoons to assist with weighing and measuring foods and fluids to ensure accuracy of quantities consumed. These instruments have been supplied by the GCHHS Study, Education and Research Trust Account (SERTA).

\section{Intervention Procedure}

All participants will follow a prescribed meal plan to meet their estimated energy needs as per the Schofield formula [64]. Meal plan macronutrient distribution will be $20 \%$ carbohydrate, $25 \%$ protein, and 55\% fat based on the Australian book, The CSIRO Low Carb Diet [65]. The meal plan contains no more than 100 g per day of dietary carbohydrate, making this intervention a low carbohydrate dietary regimen according to Feinman et al's [16] 2015 definition. Alcohol influences blood glucose levels, food and fluid choices, and quantities consumed [66]. For this reason, participants will be strongly advised to abstain from alcohol consumption during the 12-week intervention. Weekly telephone follow-up will be conducted by JP to discuss any concerns or questions participants may have. Follow-up by telephone has been shown to be an effective method to monitor medical nutrition therapy $[67,68]$. Weekly telephone appointments will also be conducted by the research teams' endocrinologist (PD) to discuss blood glucose level management and adjust insulin doses as needed.

Any hypoglycemia treatment will be recorded in the food diary and will detail when, what, and how much carbohydrate was used to treat the hypoglycemic event. If any hypoglycemic events occur, PD will discuss this with the participant during the weekly telephone appointment and advice will be provided to avoid future occurrences. Participants will check blood ketones once a week on the morning after an overnight fast to avoid diabetic ketoacidosis. If blood ketones are present $(>0.6$ $\mathrm{mmol} / \mathrm{l}$ ), participants will follow a "sick day" management plan, and, if unsure what to do, will contact PD for advice. Participants will be encouraged to follow their usual exercise habits, as no exercise advice will be given [69]. This study is unique, and if a participant feels they are unable to complete the 12 -week intervention, they may withdraw at any time.

\section{Postintervention Procedure}

At the completion of the intervention, the participant's weight (kg) will be recorded. An $\mathrm{HbA}_{1 \mathrm{c}}$ test will be performed by the research teams' CDE (DI). The online Australian diabetes-specific QoL questionnaire will be readministered. An online patient global impression of change questionnaire will be administered to determine the participants' perception of the degree of change following the intervention relating to glycemic control and QoL [70]. This questionnaire will consist of 2 
questions using a 7-point scale ("no change/has got worse" to "a great deal better/considerable improvement"). Finally, in an individual interview, each participant will be asked 5 questions regarding the CGMS experience relating to its acceptability, perception, benefits, and barriers. An interview question guide will be used to facilitate the interview. Data will be transcribed, coded, and parsed for common themes for inclusion in a publication.

\section{Potential Adverse Events}

Potential adverse events may include hypoglycemia, hyperglycemia, blood ketones, and diabetic ketoacidosis episodes. Any adverse events will be discussed by PD and the participant, and a plan will be put in place to prevent any future occurrences. However, adverse events are not expected to occur due to the safety alerts thresholds that will be set up on the CGM as recommended by the CGM use guidelines [71].

\section{Outcomes}

The primary outcomes will be divided according to the study phases. Primary outcome 1 will be related to the development and piloting of the new Australian diabetes-specific QoL questionnaire in study phase 1 . Primary outcome 2 will be related to the validation of the study-developed questionnaire in study phase 2 . Study phase 3 will produce 3 subdeliverables that will examine the association between a low carbohydrate diet and glycemic control in adults with T1DM (primary outcome 3.1), examine the association between a low carbohydrate diet and QoL in adults with T1DM (primary outcome 3.2), and investigate whether a low carbohydrate diet mediates the relationship between QoL and glycemic control in adults with T1DM (primary outcome 3.3).

This study will have no secondary study outcomes.

Figure 1 schematically shows the relationship between the study objectives. The association between QoL, low carbohydrate diet, and glycemic control variables have been represented with double-headed arrows. This indicates that the direction of the association is unclear and may be bidirectional in nature, as each variable has the potential to influence the other $[13,19,30]$.

Figure 1. The association between adults living with type 1 diabetes mellitus, quality of life, and glycemic control. CDE: credentialed diabetes educator; CHO: carbohydrate; PO: primary outcome; T1DM: type 1 diabetes mellitus.

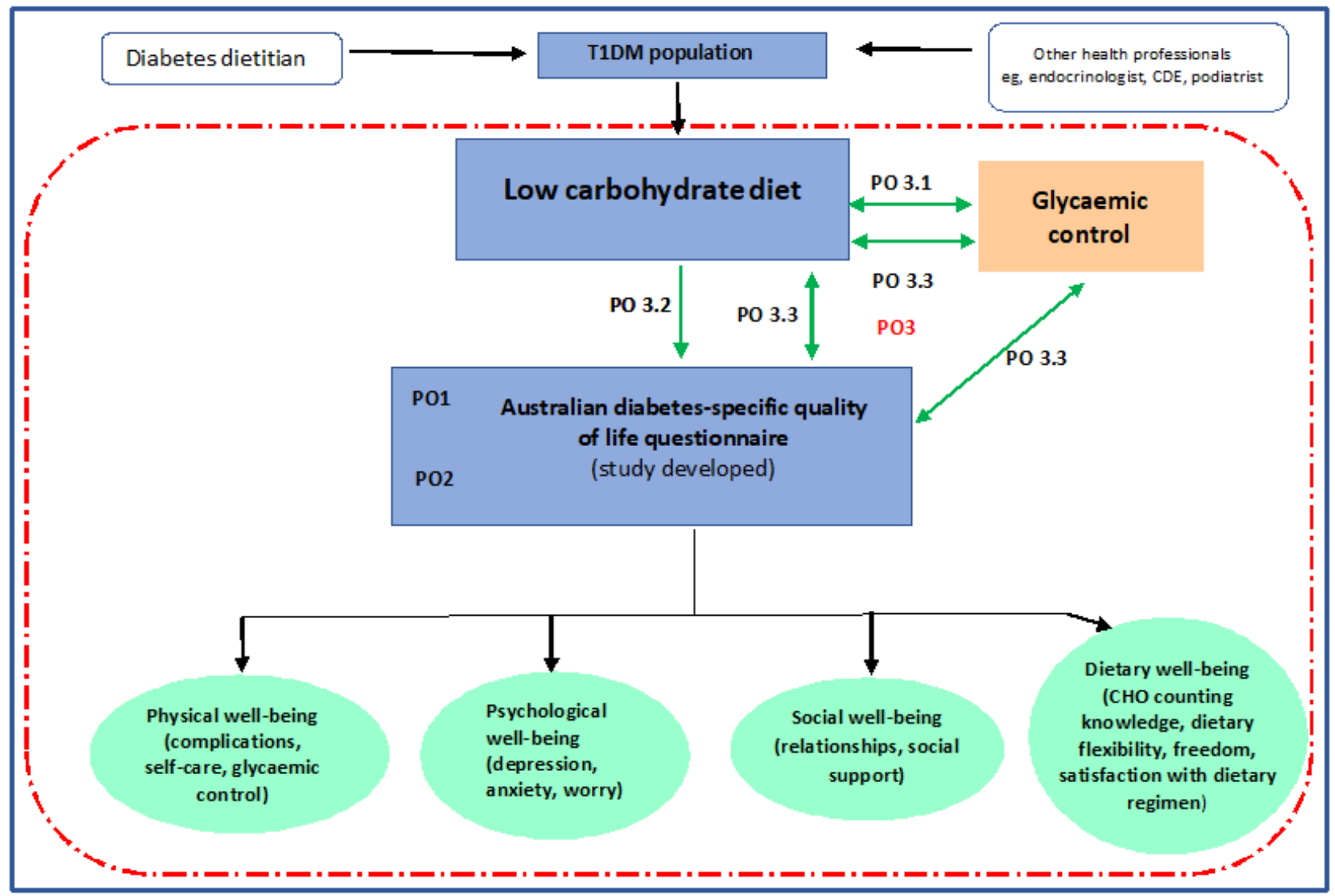

\section{Study Phase 1: Australian Diabetes-Specific QoL Questionnaire Development and Piloting}

A qualitative approach will be implemented to analyze data collected from audio-recorded participant interviews. Coding will be undertaken using an interview question guide as a framework. The question guide includes the following categories: technical aspects, formatting and layout, participant understanding of the questionnaire aim and purpose, interpretation of the questions, time taken to complete the questionnaire, and any other feedback to improve the usefulness of the questionnaire. In addition, divergence and concordance of participant opinion will be noted. Following this process, data will be cross-checked by a second CDE (trained coder). Any discrepancies will be resolved by a round table discussion 
with the study team, and questionnaire items to be revised will be determined at this forum.

\section{Study Phase 2: Online Australian Diabetes-Specific QoL Questionnaire Validation; and Study Phase 3: The Low Carbohydrate Dietary Intervention}

Data will be coded, entered into a password-protected database, checked by JP, and cross-checked by the same CDE (trained coder) from study phase 1 . Descriptive statistics will be reported using mean and SD. Study phase 2 (including subphases $2 \mathrm{a}$ and 2b) and phase 3 data will be analyzed using R statistical software version 3.6.1 or later ( $\mathrm{R}$ Foundation for Statistical Computing) [72]. Statistical significance will be set at a $P$ value <.05.

\section{Statistical Plan}

Table 4 outlines a brief summary of the study objectives, the independent and dependent variables relating to each objective, and the planned statistical analyses to be conducted.

Table 4. Brief statistical plan.

\begin{tabular}{|c|c|c|c|}
\hline Statistical objectives & Independent variable & Dependent variable & Statistical analysis \\
\hline $\begin{array}{l}\text { To develop and pilot the Australian } \\
\text { diabetes-specific quality of life } \\
\text { questionnaire }\end{array}$ & $\begin{array}{l}\text { Australian diabetes-specific quality } \\
\text { of life questionnaire }\end{array}$ & $\mathrm{N} / \mathrm{A}^{\mathrm{a}}$ & $\begin{array}{l}\text { Transcribe, code, and identify com- } \\
\text { mon themes in the interview data }\end{array}$ \\
\hline $\begin{array}{l}\text { To validate the Australian diabetes- } \\
\text { specific quality of life questionnaire } \\
\text { (study developed) }\end{array}$ & $\begin{array}{l}\text { Australian diabetes-specific quality } \\
\text { of life questionnaire }\end{array}$ & $\begin{array}{l}\text { Factorial validation indicators: root } \\
\text { mean square error of approximation, } \\
\text { comparative fit index, and Tucker- } \\
\text { Lewis index }\end{array}$ & $\begin{array}{l}\text { Exploratory factor analysis, confir- } \\
\text { matory factor analysis, and struc- } \\
\text { tural equation modelling }\end{array}$ \\
\hline $\begin{array}{l}\text { To examine the association between } \\
\text { a low carbohydrate diet and } \\
\text { glycemic control }\end{array}$ & Low carbohydrate diet & Glycemic control & $\begin{array}{l}\text { Bivariate: ANOVA }{ }^{\mathrm{b}} \text { and correla- } \\
\text { tions. } \\
\text { Multivariate: hierarchical regression } \\
\text { controlling for sociodemographic } \\
\text { covariates. }\end{array}$ \\
\hline $\begin{array}{l}\text { To investigate whether a low carbo- } \\
\text { hydrate diet mediates the relation- } \\
\text { ship between quality of life and } \\
\text { glycemic control }\end{array}$ & Low carbohydrate diet & Glycemic control and quality of life & $\begin{array}{l}\text { Bivariate: ANOVA and correlations. } \\
\text { Multivariate: hierarchical regression } \\
\text { controlling for sociodemographic } \\
\text { covariates. }\end{array}$ \\
\hline
\end{tabular}

${ }^{\mathrm{a}} \mathrm{N} / \mathrm{A}$ : not applicable

${ }^{b}$ ANOVA: analysis of variance

\section{Results}

To date, 12 participants have been recruited into phase 1 of this study. The anticipated data collection completion date for all study phases is March 2022. At present, no study results are available.

\section{Discussion}

This study is the first of its kind to examine the association between a low carbohydrate diet, QoL, and glycemic control. This cross-sectional study protocol aims to develop, pilot, and validate a diabetes-specific QoL questionnaire and determine if an association exists between QoL and glycemic control while using a low carbohydrate dietary intervention in Australian adults living with T1DM.

The strengths of this study are that, to our knowledge, no previous published research has evaluated a low carbohydrate diet and its influence on QoL and glycemic control in Australian adults living with T1DM. Moreover, this is the first study to develop and validate an Australian T1DM-specific QoL questionnaire Therefore, the strengths of this study are its unique approach.

The potential limitations of this study include the fact that, first, the Australian diabetes-specific QoL questionnaire is not available to those who are vision impaired, intellectually impaired, or have any other type of diabetes, such as T2DM and gestational diabetes mellitus. Future studies could develop resources to include these populations. Second, in study phases 1 and 2, questionnaire data will be self-reported and may have the potential to produce social desirability bias [73]. However, using self-reported data is the most feasible option for this pilot study in order for the sample size $(\mathrm{N}=364)$ and statistical validation of the questionnaire to be achieved. Third, study phase 3 has been designed as a nonrandomized intervention group pilot study that will inform the design and feasibility of a potential larger randomized control trial. Finally, in study phase 3 , there is potential selection bias: individuals who are highly motivated to improve glycemic control are more likely to participate [25].

The Australian diabetes-specific QoL questionnaire will be a useful instrument for health care professionals, including general 
practitioners, diabetes dietitians, and diabetes educators. This instrument will support health care practitioners to gain a better understanding of Australian T1DM adults' QoL perception relating to physical, psychological, social, and dietary well-being. To date, studies that have investigated the influence of a very low or low carbohydrate diet and glycemic control in adults living with T1DM have not examined QoL using a validated instrument in tandem with participants undertaking the dietary regimen [12,13,19,21,23-31]. Consequently, a validated QoL instrument is needed for clinical practice and future research to identify the QoL of Australian adults with T1DM, as no validated instrument currently exists.

It is recommended that people living with T1DM follow healthy eating dietary guidelines for the general population [3].
However, this study's dietary intervention outcomes could provide an alternative approach. Additionally, the study findings could warrant the development of a specific dietary guideline for using a low carbohydrate diet to support glycemic management and improve QoL in adults living with T1DM.

This study will generate a new validated QoL instrument which could be used in evidence-based practice and research to understand the QoL of adults with T1DM. It will also investigate the association of a low carbohydrate diet, QoL, and glycemic control in Australian adults living with T1DM. If successful, this study has the potential to have a profound impact on those living with T1DM.

\section{Acknowledgments}

This study is self-funded. We would like to thank Dexcom and GCHHS SERTA for providing the resources for this study, and the GCHHS SERTA Committee and library staff for their support.

\section{Authors' Contributions}

All authors contributed to the development of the study concept. JP authored the first version of the manuscript. The manuscript was reviewed by RJ, PD, and CKA, and further revisions were made by JP.

\section{Conflicts of Interest}

None declared.

\section{References}

1. IDF diabetes atlas, ninth edition. International Diabetes Federation. URL: http://www.diabetesatlas.org [accessed 2020-05-11]

2. Type 1 diabetes. National Diabetes Services Scheme. URL: https://www.ndss.com.au/wp-content/uploads/snapshots/2020/ ndss-data-snapshot-202006-type1-diabetes.pdf [accessed 2020-09-25]

3. Scott SN, Anderson L, Morton JP, Wagenmakers AJM, Riddell MC. Carbohydrate restriction in type 1 diabetes: a realistic therapy for improved glycaemic control and athletic performance? Nutrients 2019 May 07;11(5) [FREE Full text] [doi: 10.3390/nu11051022] [Medline: 31067747]

4. Sherwani SI, Khan HA, Ekhzaimy A, Masood A, Sakharkar MK. Significance of HbA1c test in diagnosis and prognosis of diabetic patients. Biomark Insights 2016;11:95-104 [FREE Full text] [doi: 10.4137/BMI.S38440] [Medline: 27398023]

5. Australian diabetes society position statement: individualization of Hba1c targets for adults with diabetes mellitus Australia 2009. Australian Diabetes Society. URL: https://diabetessociety.com.au/downloads/positionstatements/HbA1ctargets.pdf [accessed 2020-05-11]

6. McKnight JA, Wild SH, Lamb MJE, Cooper MN, Jones TW, Davis EA, et al. Glycaemic control of type 1 diabetes in clinical practice early in the 21st century: an international comparison. Diabet Med 2015 Aug;32(8):1036-1050. [doi: 10.1111/dme.12676] [Medline: 25510978]

7. The Diabetes Control and Complications Trial Research Group. The effect of intensive treatment of diabetes on the development and progression of long-term complications in insulin-dependent diabetes mellitus. N Engl J Med 1993 Sep 30;329(14):977-986. [doi: 10.1056/NEJM199309303291401] [Medline: 8366922]

8. Fazeli Farsani S, Brodovicz K, Soleymanlou N, Marquard J, Wissinger E, Maiese BA. Incidence and prevalence of diabetic ketoacidosis (DKA) among adults with type 1 diabetes mellitus (T1D): a systematic literature review. BMJ Open 2017 Aug 01;7(7):e016587 [FREE Full text] [doi: 10.1136/bmjopen-2017-016587] [Medline: 28765134]

9. Nutrient reference values for Australia and New Zealand including recommended dietary intakes. Australian National Health and Medical Research Council and the New Zealand Ministry of Health. 2015. URL: https://www.nhmrc.gov.au/ sites/default/files/images/nutrient-refererence-dietary-intakes.pdf [accessed 2020-10-10]

10. Vaz EC, Porfírio GJM, Nunes HRDC, Nunes-Nogueira VDS. Effectiveness and safety of carbohydrate counting in the management of adult patients with type 1 diabetes mellitus: a systematic review and meta-analysis. Arch Endocrinol Metab 2018 Jun;62(3):337-345. [doi: 10.20945/2359-3997000000045] [Medline: 29791661]

11. Giacco R, Parillo M, Rivellese AA, Lasorella G, Giacco A, D'Episcopo L, et al. Long-term dietary treatment with increased amounts of fiber-rich low-glycemic index natural foods improves blood glucose control and reduces the number of hypoglycemic events in type 1 diabetic patients. Diabetes Care 2000 Oct;23(10):1461-1466 [FREE Full text] [doi: 10.2337/diacare.23.10.1461] [Medline: 11023137] 
12. Schmidt S, Christensen MB, Serifovski N, Damm-Frydenberg C, Jensen JB, Fløyel T, et al. Low versus high carbohydrate diet in type 1 diabetes: A 12-week randomized open-label crossover study. Diabetes Obes Metab 2019 Jul;21(7):1680-1688. [doi: 10.1111/dom.13725] [Medline: 30924570]

13. Eiswirth M, Clark E, Diamond M. Low carbohydrate diet and improved glycaemic control in a patient with type one diabetes. Endocrinol Diabetes Metab Case Rep 2018;2018. [doi: 10.1530/EDM-18-0002] [Medline: 29576869]

14. Sainsbury E, Kizirian NV, Partridge SR, Gill T, Colagiuri S, Gibson AA. Effect of dietary carbohydrate restriction on glycemic control in adults with diabetes: a systematic review and meta-analysis. Diabetes Research and Clinical Practice 2018 May;139:239-252. [doi: 10.1016/j.diabres.2018.02.026]

15. Snorgaard O, Poulsen GM, Andersen HK, Astrup A. Systematic review and meta-analysis of dietary carbohydrate restriction in patients with type 2 diabetes. BMJ Open Diab Res Care 2017 Feb 23;5(1):e000354. [doi: 10.1136/bmjdrc-2016-000354]

16. Feinman RD, Pogozelski WK, Astrup A, Bernstein RK, Fine EJ, Westman EC, et al. Dietary carbohydrate restriction as the first approach in diabetes management: critical review and evidence base. Nutrition 2015 Jan;31(1):1-13. [doi: 10.1016/j.nut.2014.06.011] [Medline: 25287761]

17. Position statement: low carbohydrate eating for people with diabetes. Diabetes Australia. 2018. URL: https://www. diabetesaustralia.com.au/research-advocacy/position-statements/ [accessed 2020-05-12]

18. Turton JL, Raab R, Rooney KB. Low-carbohydrate diets for type 1 diabetes mellitus: a systematic review. PLoS One 2018;13(3):e0194987 [FREE Full text] [doi: 10.1371/journal.pone.0194987] [Medline: 29596460]

19. Krebs JD, Parry Strong A, Cresswell P, Reynolds AN, Hanna A, Haeusler S. A randomised trial of the feasibility of a low carbohydrate diet vs standard carbohydrate counting in adults with type 1 diabetes taking body weight into account. Asia Pac J Clin Nutr 2016;25(1):78-84 [FREE Full text] [doi: 10.6133/apjen.2016.25.1.11] [Medline: 26965765]

20. Anderson JW, Zeigler JA, Deakins DA, Floore TL, Dillon DW, Wood CL, et al. Metabolic effects of high-carbohydrate, high-fiber diets for insulin-dependent diabetic individuals. Am J Clin Nutr 1991 Nov;54(5):936-943. [doi:

10.1093/ajcn/54.5.936] [Medline: 1659172]

21. Ireland P, O'Dea K, Nankervis A. Short-term effects of alterations in dietary fat on metabolic control in IDDM. Diabetes Care 1992 Nov;15(11):1499-1504. [doi: 10.2337/diacare.15.11.1499] [Medline: 1468276 ]

22. Chantelau E, Sonnenberg GE, Stanitzek-Schmidt I, Best F, Altenähr H, Berger M. Diet liberalization and metabolic control in type I diabetic outpatients treated by continuous subcutaneous insulin infusion. Diabetes Care 1982;5(6):612-616. [doi: 10.2337/diacare.5.6.612] [Medline: 6927731]

23. Vernon MC, Mavropoulos J, Transue M, Yancy WS, Westman EC. Clinical experience of a carbohydrate-restricted diet: effect on diabetes mellitus. Metabolic Syndrome and Related Disorders 2003 Sep;1(3):233-237. [doi: 10.1089/154041903322716714] [Medline: 18370667]

24. Nielsen JV, Gando C, Joensson E, Paulsson C. Low carbohydrate diet in type 1 diabetes, long-term improvement and adherence: a clinical audit. Diabetol Metab Syndr 2012 May 31;4(1):23 [FREE Full text] [doi: 10.1186/1758-5996-4-23] [Medline: 22650646]

25. Nielsen JV, Jönsson E, Ivarsson A. A low carbohydrate diet in type 1 diabetes: clinical experience--a brief report. Ups J Med Sci 2005;110(3):267-273. [doi: 10.3109/2000-1967-074] [Medline: 16454166]

26. O' Neill DF, Westman EC, Bernstein RK. The effects of a low-carbohydrate regimen on glycemic control and serum lipids in diabetes mellitus. Metab Syndr Relat Disord 2003 Dec;1(4):291-298. [doi: 10.1089/1540419031361345] [Medline: $\underline{18370654]}$

27. Bernstein RK. Virtually continuous euglycemia for $5 \mathrm{yr}$ in a labile juvenile-onset diabetic patient under noninvasive closed-loop control. Diabetes Care 1980;3(1):140-143. [doi: 10.2337/diacare.3.1.140] [Medline: $\underline{6996959]}$

28. Ranjan A, Schmidt S, Damm-Frydenberg C, Holst JJ, Madsbad S, Nørgaard K. Short-term effects of a low carbohydrate diet on glycaemic variables and cardiovascular risk markers in patients with type 1 diabetes: a randomized open-label crossover trial. Diabetes Obes Metab 2017 Oct;19(10):1479-1484. [doi: 10.1111/dom.12953] [Medline: 28345762]

29. Leow ZZX, Guelfi KJ, Davis EA, Jones TW, Fournier PA. The glycaemic benefits of a very-low-carbohydrate ketogenic diet in adults with Type 1 diabetes mellitus may be opposed by increased hypoglycaemia risk and dyslipidaemia. Diabet Med 2018 May 08. [doi: 10.1111/dme.13663] [Medline: 29737587]

30. Raab R. The low carbohydrate/low insulin regimen - personal experience in type 1 diabetes. Pract Diab Int 2003 May;20(4):140-142. [doi: 10.1002/pdi.481]

31. Kwiendacz H, Domek M, Nabrdalik K, Maj-Podsiadlo A, Marcisz M, Drozdz K. An unusual use of personal insulin pump by a patient with type 1 diabetes on a ketogenic diet - a case report. Clin. Diabetol 2019;8(4):223-226. [doi: $10.5603 / \mathrm{dk} .2019 .0017]$

32. Global report on diabetes.: World Health Organization; 2016. URL: https://apps.who.int/iris/bitstream/handle/10665/204871/ 9789241565257 eng.pdf;jsessionid=7A48BB19A9F52DC79DFE5690B4E8B921?sequence=1 [accessed 2020-03-10]

33. Roy T, Lloyd CE. Epidemiology of depression and diabetes: a systematic review. J Affect Disord 2012 Oct;142 Suppl:S8-21. [doi: 10.1016/S0165-0327(12)70004-6] [Medline: 23062861]

34. Diabetes: the silent pandemic and its impact on Australia. Diabetes Australia.: Baker IDI; 2012. URL: https://www. diabetesaustralia.com.au/wp-content/uploads/Diabetes-the-silent-pandemic-and-its-impact-on-Australia.pdf [accessed 2020-10-12] 
35. Speight J, Reaney MD, Barnard KD. Not all roads lead to Rome-a review of quality of life measurement in adults with diabetes. Diabet Med 2009 Apr;26(4):315-327. [doi: 10.1111/j.1464-5491.2009.02682.x] [Medline: 19388959]

36. Polonsky W. Understanding and assessing diabetes-specific quality of life. Diabetes spectrum 2000;13(1):36.

37. World Health Organization. The World Health Organization Quality of Life assessment (WHOQOL): position paper from the World Health Organization. Soc Sci Med 1995 Nov;41(10):1403-1409. [doi: 10.1016/0277-9536(95)00112-k] [Medline: $\underline{8560308]}$

38. Burroughs TE, Desikan R, Waterman BM, Gilin D, McGill J. Development and validation of the Diabetes Quality of Life Brief Clinical Inventory. Diabetes Spectrum 2004 Jan 01;17(1):41-49. [doi: 10.2337/diaspect.17.1.41]

39. Bergner M. Quality of life, health status, and clinical research. Med Care 1989 Mar;27(3 Suppl):S148-S156. [doi: 10.1097/00005650-198903001-00012] [Medline: 2646487]

40. Bowling A. Measuring Health. A Review of Quality of Life Measurement Scales. Maidenhead: Open University Press; 2005.

41. Rubin R. Diabetes and quality of life. Diabetes spectrum 2000;13(1):21.

42. El Achhab Y, Nejjari C, Chikri M, Lyoussi B. Disease-specific health-related quality of life instruments among adults diabetic: a systematic review. Diabetes Res Clin Pract 2008 May;80(2):171-184. [doi: 10.1016/j.diabres.2007.12.020] [Medline: 18279993]

43. Torrance GW. Utility approach to measuring health-related quality of life. J Chronic Dis 1987;40(6):593-603. [doi: 10.1016/0021-9681(87)90019-1] [Medline: 3298297]

44. Haas BK. A multidisciplinary concept analysis of quality of life. West J Nurs Res 1999 Dec;21(6):728-742. [doi: 10.1177/01939459922044153] [Medline: 11512210]

45. Sato E, Suzukamo Y, Miyashita M, Kazuma K. Development of a diabetes diet-related quality-of-life scale. Diabetes Care 2004 Jun;27(6):1271-1275. [doi: 10.2337/diacare.27.6.1271] [Medline: 15161774]

46. Jing X, Chen J, Dong Y, Han D, Zhao H, Wang X, et al. Related factors of quality of life of type 2 diabetes patients: a systematic review and meta-analysis. Health Qual Life Outcomes 2018 Sep 19;16(1):189 [FREE Full text] [doi: 10.1186/s12955-018-1021-9] [Medline: 30231882]

47. Pereira EV, Tonin FS, Carneiro J, Pontarolo R, Wiens A. Evaluation of the application of the Diabetes Quality of Life Questionnaire in patients with diabetes mellitus. Arch Endocrinol Metab 2020 Feb;64(1):59-65. [doi: 10.20945/2359-3997000000196] [Medline: 32187271]

48. Bott U, Mühlhauser I, Overmann H, Berger M. Validation of a diabetes-specific quality-of-life scale for patients with type 1 diabetes. Diabetes Care 1998 May;21(5):757-769. [doi: 10.2337/diacare.21.5.757] [Medline: 9589237]

49. The Diabetes Control and Complications Trial Research Group. Reliability and validity of a diabetes quality-of-life measure for the diabetes control and complications trial (DCCT). Diabetes Care 1988 Oct;11(9):725-732. [doi: 10.2337/diacare.11.9.725] [Medline: 3066604]

50. Ingersoll GM, Marrero DG. A modified Quality-of-Life Measure for Youths: psychometric properties. Diabetes Educ 2016 Jun 30;17(2):114-118. [doi: 10.1177/014572179101700219] [Medline: 1995281]

51. Trawley S, Baptista S, Browne JL, Pouwer F, Speight J. The use of mobile applications among adults with type 1 and type 2 diabetes: results from the second MILES-Australia (MILES-2) study. Diabetes Technology \& Therapeutics 2017 Dec;19(12):730-738. [doi: 10.1089/dia.2017.0235] [Medline: 29028442]

52. Ware JE, Sherbourne CD. The MOS 36-ltem Short-Form Health Survey (SF-36). Medical Care 1992;30(6):473-483. [doi: 10.1097/00005650-199206000-00002] [Medline: 1593914]

53. Welch GW, Jacobson AM, Polonsky WH. The Problem Areas in Diabetes Scale: An evaluation of its clinical utility. Diabetes Care 1997 May 01;20(5):760-766. [doi: 10.2337/diacare.20.5.760] [Medline: 9135939]

54. Jani R, Byrne R, Love P, Agarwal C, Peng F, Yew YW, et al. The environmental and bitter taste endophenotype determinants of picky eating in Australian school-aged children 7-12 years-a cross-sectional pilot study protocol. Int J Environ Res Public Health 2020 Feb 29;17(5) [FREE Full text] [doi: 10.3390/ijerph17051573] [Medline: 32121357]

55. Dworkin SL. Sample size policy for qualitative studies using in-depth interviews. Arch Sex Behav 2012 Sep 12;41(6):1319-1320. [doi: 10.1007/s10508-012-0016-6] [Medline: 2298493]

56. Anthoine E, Moret L, Regnault A, Sébille V, Hardouin J. Sample size used to validate a scale: a review of publications on newly-developed patient reported outcomes measures. Health Qual Life Outcomes 2014 Dec 09;12:176 [FREE Full text] [doi: 10.1186/s12955-014-0176-2] [Medline: 25492701]

57. Alvarado-Martel D, Ruiz Fernández MA, Cuadrado Vigaray M, Carrillo A, Boronat M, Expósito Montesdeoca A, et al. ViDa1: The development and validation of a new questionnaire for measuring health-related quality of life in patients with type 1 diabetes. Front Psychol 2017;8:904 [FREE Full text] [doi: 10.3389/fpsyg.2017.00904] [Medline: 28620331]

58. Mannucci E, Ricca V, Bardini G, Rotella C. Well-being enquiry for diabetics: a new measure of diabetes-related quality of life. Diabetes Nutr Metab 1996;9(2):a.

59. Shen W, Kotsanos JG, Huster WJ, Mathias SD, Andrejasich CM, Patrick DL. Development and validation of the diabetes quality of life clinical trial questionnaire. Medical Care 1999;37:AS45-AS66. [doi: 10.1097/00005650-199904001-00008] [Medline: 30632972] 
60. American Diabetes Association. Facilitating behavior change and well-being to improve health outcomes: standards of medical care in diabetes. Diabetes Care 2020 Jan;43(Suppl 1):S48-S65. [doi: 10.2337/dc20-S005] [Medline: 31862748]

61. 2016 Census QuickStats. Australian Bureau of Statistics. URL: http://quickstats.censusdata.abs.gov.au/census services/ getproduct/census/2016/quickstat/POA4215?opendocument [accessed 2020-09-22]

62. Harris J, McGee A, Andrews F, D'Souza J, Sproston K. The national survey of people with diabetes 2006. NHS Patient Surveys. 2007. URL: http://www.nhssurveys.org/Filestore/documents/Diabetes key findings rpt.pdf [accessed 2020-09-15]

63. Lee PH, Macfarlane DJ, Lam TH, Stewart SM. Validity of the International Physical Activity Questionnaire Short Form (IPAQ-SF): a systematic review. Int J Behav Nutr Phys Act 2011;8:115 [FREE Full text] [doi: 10.1186/1479-5868-8-115] [Medline: 22018588]

64. Schofield WN. Predicting basal metabolic rate, new standards and review of previous work. Hum Nutr Clin Nutr 1985;39 Suppl 1:5-41. [Medline: 4044297]

65. Brinkworth G, Taylor P. The CSIRO Low-Carb Diet. Sydney: Pan Macmilliam Australia; 2017.

66. Charlton J, Gill J, Elliott L, Whittaker A, Farquharson B, Strachan M. A review of the challenges, glycaemic risks and self - care for people with type 1 diabetes when consuming alcoholic beverages. Pract Diab 2020 Feb 06;37(1):7. [doi: $10.1002 /$ pdi.2253]

67. Sakane N, Kotani K, Takahashi K, Sano Y, Tsuzaki K, Okazaki K, et al. Effects of telephone-delivered lifestyle support on the development of diabetes in participants at high risk of type 2 diabetes: J-DOIT1, a pragmatic cluster randomised trial. BMJ Open 2015 Aug 19;5(8):e007316 [FREE Full text] [doi: 10.1136/bmjopen-2014-007316] [Medline: 26289448]

68. Wu L, Forbes A, Griffiths P, Milligan P, While A. Telephone follow-up to improve glycaemic control in patients with Type 2 diabetes: systematic review and meta-analysis of controlled trials. Diabet Med 2010 Nov;27(11):1217-1225. [doi: 10.1111/j.1464-5491.2010.03113.x] [Medline: 20950378]

69. Kapitza C, Hövelmann U, Nosek L, Kurth H, Essenpreis M, Heinemann L. Continuous glucose monitoring during exercise in patients with type 1 diabetes on continuous subcutaneous insulin infusion. J Diabetes Sci Technol 2010 Jan 01;4(1):123-131 [FREE Full text] [doi: 10.1177/193229681000400116] [Medline: 20167176]

70. Hurst H, Bolton J. Assessing the clinical significance of change scores recorded on subjective outcome measures. J Manipulative Physiol Ther 2004 Jan;27(1):26-35. [doi: 10.1016/j.jmpt.2003.11.003] [Medline: 14739871]

71. Danne T, Nimri R, Battelino T, Bergenstal RM, Close KL, DeVries JH, et al. International consensus on the use of continuous glucose monitoring. Diabetes Care 2017 Dec;40(12):1631-1640 [FREE Full text] [doi: 10.2337/dc17-1600] [Medline:

29162583]

72. R Core Team. R: A language and environment for statistical computing. R Foundation for Statistical Computing, Vienna, Austria. URL: http://www.R-project.org/ [accessed 2020-01-15]

73. Althubaiti A. Information bias in health research: definition, pitfalls, and adjustment methods. J Multidiscip Healthc 2016;9:211-217 [FREE Full text] [doi: 10.2147/JMDH.S104807] [Medline: 27217764]

\author{
Abbreviations \\ CDE: credentialed diabetes educator \\ CGMS: continuous glucose monitoring system \\ DQOL: Diabetes Quality of Life \\ GCHHS: Gold Coast Hospital and Health Service \\ $\mathbf{H b A}_{1 \mathbf{c}}$ : glycated hemoglobin \\ MOS SF-36: Medical Outcomes Study 36-Item Short Form Health Survey \\ PAID: Problem Areas in Diabetes \\ QoL: quality of life \\ QR: quick response \\ SERTA: Study, Education and Research Trust Account \\ T1DM: type 1 diabetes mellitus \\ T2DM: type 2 diabetes mellitus
}


Edited by G Eysenbach; submitted 16.10.20; peer-reviewed by M D'Emden, R Khan, M Eiswirth; comments to author 25.11.20; revised version received 21.12.20; accepted 21.01.21; published 26.03.21

Please cite as:

Paul J, Jani R, Davoren P, Knight-Agarwal C

Association Between a Low Carbohydrate Diet, Quality of Life, and Glycemic Control in Australian Adults Living With Type 1 Diabetes: Protocol for a Mixed Methods Pilot Study

JMIR Res Protoc 2021;10(3):e25085

URL: https://www.researchprotocols.org/2021/3/e25085

doi: $\underline{10.2196 / 25085}$

PMID: $\underline{33769300}$

(CJanine Paul, Rati Jani, Peter Davoren, Catherine Knight-Agarwal. Originally published in JMIR Research Protocols (http://www.researchprotocols.org), 26.03.2021. This is an open-access article distributed under the terms of the Creative Commons Attribution License (https://creativecommons.org/licenses/by/4.0/), which permits unrestricted use, distribution, and reproduction in any medium, provided the original work, first published in JMIR Research Protocols, is properly cited. The complete bibliographic information, a link to the original publication on http://www.researchprotocols.org, as well as this copyright and license information must be included. 